Canadian Journal of Action Research

Volume 22, Issue 1, 2021, pages 45-68

\title{
EXPLORING VETERAN TEACHERS' COLLABORATIVE ACTION RESEARCH EXPERIENCES THROUGH A SCHOOL-UNIVERSITY PARTNERSHIP: “OLD DOGS” TRY NEW TRICKS
}

\author{
Mary Frances (Molly) Buckley-Marudas \\ Cleveland State University
}

Charles Ellenbogen

Cleveland Metropolitan School District

\author{
John Dutton \\ Cleveland Metropolitan School District \\ Grace Hui-Chen Huang \\ Cleveland State University
}

\section{Sarah Schwab \\ Cleveland Metropolitan School District}

\begin{abstract}
This article shares insights from the experiences of three high school practitioners and two university faculty who participated in a school-university-based action research program as a voluntary part of the teachers' professional development. The three high school practitioners conducted action research projects around questions that stemmed from and were relevant to their own teaching practice. As part of the action research program, the practitioners were paired with university faculty to support the research. Building on practitioner inquiry traditions and critical case study methodologies, this study used qualitative methods to explore the experiences of practitioner action research processes. Drawing on in-person meeting notes and reflective memos, four key ideas emerged: Infrastructure, We are all Partners in Education, Engaging Pathway for Experienced Teachers, and Challenges. Insights gained from this inquiry will have implications for professional practices in the areas of school-university partnership, professional development, and action research process.
\end{abstract}

KeY WoRds: Collaborative action research; Partnership; Practitioner researcher; Professional development; Critical friend 


\section{InTRODUCTION}

Professional development (PD) has long been integrated into the field of teaching. At its core, the intent of teacher PD is to improve student learning. This may include efforts to enrich teachers' existing instructional practices and/or efforts to introduce new approaches to teaching and learning. In the last two decades, with increased attention to standards-driven reforms and top-down accountability measures, the field of education has seen an increase in teacher PD time that is heavily focused on making sense of student data in the service of improving student learning, which is most often defined by students' performance on standardized tests. Teachers' levels of experiences and expertise are often not considered in the professional development sessions, impacting the effectiveness of the PD (Ado, 2013; Bransford et al., 2000; Van Driel et al., 2001). Currently, many experienced teachers are accustomed to attending PD sessions that were pre-determined by administrators without much input on topics. However, one size does not fit all. Vanderhye (2015) suggests that asking the entire staff, or even a grade level, to work on identical PD, is anathema to skillful professionals.

Veteran teachers, in particular, are reported to learn differently than novices do (Ado, 2013). They may need different strategies and opportunities to motivate them to pursue professional growth. In recent years, action research has emerged as a useful form of PD. Ado (2013) indicates that action research empowers novice teachers. In and through the action research process, teachers can expand their capacities as practitioners and simultaneously address the specific needs of teachers, classrooms, and/or students. We approach this work with the belief that a teacher-driven action research process could be a powerful tool for veteran teachers' ongoing PD. We, the five co-authors of this article, think this is particularly important in school districts in urban centers, where there is a tendency to invest in PD targeted towards new or less experienced teachers.

This article focuses on the five authors' experiences with a year-long action research program. Three of us, John, Charles, and Sarah, are experienced high school practitioners, who volunteered to participate in the year-long action research program hosted by our school's partner university. Two of us, Molly and Grace, are full-time university faculty members who participated in the action research program as faculty partners. John, Charles, and Sarah are full-time teachers at Campus International High School, a public high school in the Cleveland Metropolitan School District (CMSD). As a district, CMSD faces many of the challenges (e.g., absenteeism, low retention, and low graduation rates) associated with urban districts around the United States. The action research program at the center of this inquiry was facilitated by Cleveland State University (CSU), a local partner university to Campus International High School. Campus International High School (CIHS) is located on the campus of the partner university, where Molly and Grace are on the faculty. Cleveland State University (CSU) defines itself as an urban serving institution. The action research program is part of the larger school-university partnership between the two institutions. In the fall, CSU project directors introduced the project to CIHS teachers during a staff meeting and invited all interested teachers to join in the year-long project. 
The intent of our collaborative inquiry was twofold. First, we hoped to gain a better understanding of the value of the action research experience for current practitioners, especially more experienced practitioners. For example, we hoped to gain a more nuanced understanding of why experienced practitioners chose to participate, what they gained from their participation, and how action research shaped their professional development.

Second, we aimed to examine the range of challenges and possibilities associated with participation in the action research program for high school practitioners and university faculty. Although we will highlight the three specific projects conducted by John, Charles, and Sarah, our emphasis is on the possibilities and challenges associated with the partnership and collaboration of this approach to professional development. Collaboration, as signaled in the title of the program, is critical to the existence and the design of the program as a partnership initiative between the university and the PK-12 school. This work has implications for those interested in adopting or enhancing existing teacher action research projects and programs as well as school-university partners who want to expand, deepen or improve the existing partnership.

\section{LITERATURE REVIEW \& CONCEPTUAL FrameWORK}

Our work draws on three bodies of work. Specifically, our work is informed by research and scholarship in the following fields: 1) collaborative action research, 2) schooluniversity partnerships, and 3) action research as professional development.

Collaborative Action Research (CAR) traditions informed the early stages of the design and framework of this program. CAR is a process where the school community, including teachers or administrators, identifies a specific problem in the school, asks questions, collectively plans and implements the plan for gathering information, and analyzes data to resolve the problem (Bruce et al., 2011). The process is not intended to generalize findings, but to solve specific problems identified by the school community (Gordon, 2008).

Collaborative partnership is an essential component of the inquiry. Collaborators are empowered to foster democratic ideals and embody transformative classroom practices and can lead to larger social transformation through grassroots efforts (Cooper \& Gause, 2007; Nagda et al., 2003). With socioeconomic, academic, linguistic, and cultural challenges in urban school settings, collaborative action research is particularly suitable to address the complexities of issues (Razfar, 2011). It helps teachers ask critical questions, pose problems, develop new understandings, and take action (Nagda et al., 2003). The primary goals of CAR are to improve teaching practice and student learning, empower educators, and transform school cultures (Calhoun, 2002; Gordon, 2008).

Current research and literature on school-university partnership documents the large number of collaborations that occur between PK-12 schools and university researchers (Bruce et al., 2011). University researchers and PK-12 educators contribute different kinds of expertise and perspectives. To cultivate a thriving partnership, it is critical to develop a partnership that benefits both the university and PK-12 school. The primary goal is to generate better outcomes for student learning and development, but another critical 
component of a strong partnership is to develop opportunities for all parties of the partnership, including PK-12 practitioners, student interns, and university faculty to learn from each other, and create a culture of learning community, a culture of change (Ball \& Cohen, 1999; Reischl et al., 2017).

Existing literature suggests that one aspect of a strong school-university partnership is the fostering of critical friends. Much of this literature focuses on the university faculty's role as critical friends in the field of education (Carrington \& Robinson, 2004; Deuchar, 2008; Kember, 2000; McLaughlin \& Black-Hawkins, 2004). According to Nelson (2008), university faculty should provide support and expertise in the proper amounts and at the appropriate junctures to keep the work moving forward. Critical friends are characterized as trusted outsiders who can support the school improvement process, including asking provocative questions, providing data to be examined through other lenses, and offering a critique of a person's work (Foulger, 2010, Gordon, 2008; Oja \& Smulvan, 1989; Swaffield, 2007; Wennergen \& Ronnerman, 2006).

Although there is extensive attention to the aforementioned constructions of critical friends in the existing body of literature, we found little attention to the reciprocal role that practitioners play as critical friends to the university faculty. We do not see an examination of how practitioners, by engaging in the CAR process, enrich the knowledge of university faculty and connect university faculty to the broader educational field. We hope that our work can add to and extend the dominant constructions of critical friends within a schooluniversity partnership.

Finally, we draw on the existing literature on action research as professional development. The PK-12 educational context in the United States public school is a complex landscape. The student population is increasingly diverse concerning factors including race, country of origin, language, socio-economic status, special education needs, and more. School reform efforts over the last two decades have led to changes in school design models, increased school choice, and fewer neighborhood schools. Additionally, teachers are charged with integrating new technologies into their instructional practice. In this context, it is important that educators have a variety of tools to address students' diverse learning and developmental needs and the changes in school and classroom design.

Action research has been documented to empower teachers to take control of their own PD to improve their teaching practices (Ado, 2013; Herrera, 2018). As Kemmis and McTaggart (2005) assert, CAR is a way to give participants a sense of agency in the "development and evolution of their own practice, their understandings of their practices, and the situations in which they practice by collaboratively changing the ways in which they participate with others in these practices" (p. 563). It empowers practitioners to monitor their instructional approaches autonomously with a goal to challenge and improve their practice through their own research (Kayaoglu, 2015). In connection with the capacity to motivate veteran teachers, Vanderhye (2015) suggests using action research as a tool to retain veteran teachers 
Action research is documented as a systematic way to improve practice. According to Kayaoglu (2015), "Action research is a deliberate solution and improvement-oriented systematic investigation undertaken personally or by a group on participants' own daily practices in social and educational situations with a view to pursuing further informed action or changing future practices" (p. 142). Action research can also help to create a democratic culture in a classroom and/or school where teachers give students a voice by learning with them about the learning and teaching practices during the action research process. Additionally, the practitioner researcher can take charge of their own path with the knowledge or data learned, to improve the classroom learning environment. The impact inside the classroom could have ripple effects on the entire school (Herrera, 2018; Nelson, 2015; Noffke, 1997).

The inquiry aimed to understand the value of the action research experiences for the three practitioners and examine the challenges and possibilities of the partnership experiences for all participants, including the practitioners and the university faculty. This qualitative study used practitioner inquiry traditions (Cochran-Smith \& Lytle, 2009) and critical case study methodologies (Yin, 2003). We drew on qualitative methods to consider the range and variation of ways practitioners made sense of their decision to conduct an action research project related to their practice.

\section{ConteXt}

The context for this project includes the context of the overarching action research program that guided the work as well as the specific context for the three projects featured in this article. Although the focus of this work is on what was learned, individually and collectively, in and through all of our participation in action research, we believe it is important to have a brief overview of the purpose and goals of the three school-based practitioners' action research projects.

\section{The School-University Action Research Program}

Launched in 2013, Cleveland State University's (CSU) Action Research Program supports PK-12 practitioners who choose to conduct action research in partnership with university faculty. This project is a collaborative effort between CSU and Cleveland public schools. During the year-long process, interested school practitioners are paired with university faculty based on an overlap in disciplines, research topics, or research methods. The members of the paired teams meet and develop a plan for their work. The goal is to design a plan that supports teacher-led projects that are relevant and authentic to practitioners' local practices. Unlike more traditional PD, this is a voluntary and practitioner-driven PD. Practitioners decide upon a topic of interest and a research question. Together, the paired team identify a research question(s), plan and implement an intervention, collect data, analyze data to answer the questions, and identify a strategy to address the problem (Bruce et al., 2011). The primary aims of these research projects are to inform educational practice, improve student learning, empower practitioners, and transform school cultures. 
The program included four phases:

Phase 1: Recruitment and Pairing. The program held information sessions to recruit practitioners (e.g., administrators, teachers, counselors, etc.) and university faculty. The PK-12 practitioners and university faculty were paired based on shared interests. In collaboration with the university faculty, practitioners developed and launched a year-long action research project.

Phase 2: Professional Development (PD). Each action research team moved forward with their one-on-one PD sessions. The program offered a group PD in a roundtable discussion format. During this session, PK-12 practitioners presented their projects-in-progress with university faculty discussants.

Phase 3: Action Research Symposium. The program held a culminating action research symposium to showcase PK-12 practitioners' work. At this event, the researchers introduced their work and engaged in dialogue with faculty conversants and other attendees.

Phase 4: Professional Presentation Opportunity. The program encouraged practitioneruniversity faculty research teams to collaborate and disseminate their projects and practices. Since 2013, research teams have conducted over twenty presentations in professional conferences and published numerous articles.

Between 2013-2019, 105 action research projects have been completed, with approximately 30 practitioners and 15 university faculty participating each year. In this article, we feature three "telling cases" (Mitchell, 1984) of action research projects conducted by three practitioners at CIHS. CIHS is an urban, non-selective public high school. The selected projects were telling cases of experienced teachers who saw the project through to completion and applied to participate in presenting their work at an educational research conference. The first project took place outside of the structured academic classroom and the last two projects were situated within high school classrooms. Given our focus on the collaborative and partnership aspects of this work, a complete description and analysis of the three projects are outside the scope of this article, yet we will share a glimpse of each project as context. See Table 1 below for a brief snapshot of each project.

\section{Project 1: "Leading the Way: Considering the Unique Experiences and Characteristics of Students in a High School's Inaugural Class"}

Sarah's project focused on the $9^{\text {th }}$ grade students who began in 2017 as the first and only class at CIHS. This inaugural class would move through school always being the oldest. Sarah noticed that there were characteristics and tendencies of the students that were unlike other high school classes she had taught. Sarah and her faculty partner, Molly, found news stories and personal anecdotes about this experience, yet little research regarding the benefits or challenges of an inaugural class in a school that grows one grade at a time. The purpose of Sarah's project was to explore student traits and their experiences in the 
inaugural class as well as their impact on school culture. Sarah surveyed teachers, administrators, and staff members as well as the students themselves about their experiences. Sarah's study indicated that although the teachers and students had similar ideas about the characteristics of this leading class, their interpretation or impression of how those characteristics informed the school culture were distinct.

Teachers overwhelmingly commented on the leadership qualities of this class and how they had stepped up to lead in ways unexpected for 9th and 10th graders. At the same time teachers tended to report a lag in academic skills such as focus and motivation and some social emotional issues where the maturity of older peers would be helpful. Students reported being happy as the oldest and being confident that they did not "need" older students. Leadership was also a common theme. Many commented that the class was "united" and focused on the camaraderie induced by always being the oldest. Students also indicated their-feeling like "test subjects" to try out new programs or new ways of doing things as the school found its stride.

Teachers saw a bigger concern academically in not having students ahead of this class modeling college preparedness and upper level classes and work ethic. Students, conversely, claimed a clear understanding of the rest of high school and what lay ahead of them. This has implications for how students approach the academic work of the school and places the burden of clearly demonstrating the path of each academic subject on the teachers and guidance counselors. Aside from being able to support her school in thinking of ways to both celebrate leadership and proactively fill in gaps for these students, this research would benefit any school using this same model to launch a new school, but also as consideration for schools and districts starting new programs or policies.

\section{Project 2: Storytelling in the Science Classroom}

Using narratives or stories as an instructional tool is a natural way of putting information into context that leads to effective learning. Yet, science educators rarely use narratives in lieu of textbooks, demonstrations, experiments or other methodologies. This project considered: How could storytelling improve students' comprehension and retention of fundamental scientific concepts? This research aimed to understand how using narratives as an instructional method related to students' academic performance in Biology classrooms. The participants were 165 ninth and tenth grade students enrolled in Biology classes at CIHS.

John wrote three narratives for the ecology unit, addressing the ecological concepts of behavioral biology, the carbon cycle, and ecological structure which also had an informational text alternative. Each lesson has an associated activity to do after the narrative or informational text in order to reinforce the information presented. The behavioral biology narrative ("Seeing is Believing") guided students through a fictional poster presentation about real scientific studies. The carbon cycle narrative ("Carbon Cycle Game") took readers through a time travel story using the perspective of a high schooler. The ecological structure narrative ("No Paine, No Gain") embellished the account of a wellknown researcher. 
Table 1: Overview of the CIHS Practitioner Research Projects

\begin{tabular}{|c|c|c|c|c|}
\hline Researchers & Project Title & Purpose & Data collection & Findings \\
\hline $\begin{array}{l}\text { Sarah (CIHS) } \\
\& \\
\text { Molly (CSU) }\end{array}$ & $\begin{array}{l}\text { Leading the Way: } \\
\text { Considering the } \\
\text { Unique } \\
\text { Experiences \& } \\
\text { Characteristics of } \\
\text { Students in a High } \\
\text { School's Inaugural } \\
\text { Class }\end{array}$ & $\begin{array}{l}\text { Explore the traits and } \\
\text { experiences of } \\
\text { students in the school's } \\
\text { inaugural class and } \\
\text { consider their impact } \\
\text { on school culture } \\
\text { l }\end{array}$ & $\begin{array}{l}\text { Participants: teachers, } \\
\text { administrators, staff, and } \\
\text { s students } \\
\text { Data source: Surveys }\end{array}$ & $\begin{array}{l}\text { - Teachers and students had similar ideas about the characteristics of this leading class, yet } \\
\text { their interpretation or impression of how those characteristics informed the school culture were } \\
\text { distinct } \\
\text { Teachers: Commented on the leadership qualities of this class and how they have stepped up to } \\
\text { lead in ways unexpected for 9th -10th graders; reported a tendency to lag in academic skills such } \\
\text { as focus and motivation and some social emotional issues where the maturity of older peers wou } \\
\text { be helpful. Voiced concern academically without older students modeling college preparedness } \\
\text { and upper level classes and work ethic } \\
\text { Students: Reported being happy as the oldest and being confident that they did not "need" older } \\
\text { students; indicated feeling like "test subjects" to try out new programs or new ways of doing } \\
\text { things as the school has found its stride; and, claimed a clear understanding of the rest of high } \\
\text { school and what lay ahead of them } \\
\text { Leadership was a common theme. Many commented that the class was "united" and focused on } \\
\text { the camaraderie induced by always being the oldest }\end{array}$ \\
\hline John (CIHS) & $\begin{array}{l}\text { Storytelling in the } \\
\text { Science } \\
\text { Classroom }\end{array}$ & $\begin{array}{l}\text { Examine how the use } \\
\text { of narratives as an } \\
\text { instructional method } \\
\text { related to students' } \\
\text { academic performance } \\
\text { in high school Biology } \\
\text { classrooms }\end{array}$ & $\begin{array}{l}\text { Participants: } 165 \text { ninth } \\
\text { and tenth grade students } \\
\text { enrolled in Biology } \\
\text { classes } \\
\text { Data collection: } \\
\text { Pre-test, post-test }\end{array}$ & $\begin{array}{l}\text { - For the } 34 \text { students who received the "Seeing is Believing" story versus the control group (n=24) } \\
\text { that received informational text, the result was } 90 \% \text { more growth on a post-test than growth } \\
\text { shown by the control group. } \\
\text { For "Climate Change Game", there was } 100 \% \text { growth for students who received the story versus } \\
\text { the control group. For the } 31 \text { students who received "No Paine No Gain," the final result was } 50 \% \\
\text { The impact of lunch on student performance was also analyzed in order to determine if this was } \\
\text { an additional compounding variable. The final result for pre-lunch students was - } 2 \% \text { whereas for } \\
\text { post-lunch, it was } 10 \% \text {. } \\
\text { - Students who received all three stories resulted in greater comprehension and/or retention of } \\
\text { information, compared to those in the control group, there was a correlation between learning } \\
\text { through stories and better overall performance. Students receiving stories outperformed student } \\
\text { not receiving stories, even if those stories did not individually show positive results over their } \\
\text { informational text corollary. }\end{array}$ \\
\hline $\begin{array}{l}\text { Charles (CIHS) } \\
\& \\
\text { Molly (CSU) }\end{array}$ & $\begin{array}{l}\text { Fostering } \\
\text { Participatory } \\
\text { Literacies in } \\
\text { Language \& } \\
\text { Literature with } \\
\text { Student-authored } \\
\text { Podcasts }\end{array}$ & $\begin{array}{l}\text { Examine specific } \\
\text { approaches used in a } \\
10^{\text {th }} \text { grade Language \& } \\
\text { Literature podcasting } \\
\text { unit to foster digital } \\
\text { literacies as an integral } \\
\text { part of the curriculum }\end{array}$ & $\begin{array}{l}\text { Participants: Students in } \\
\text { Charles's 10th grade } \\
\text { Language \& Literature } \\
\text { classroom } \\
\text { l Research method: Case } \\
\text { studies }\end{array}$ & $\begin{array}{l}\text { - Practice listening: the work required deep listening and teaching the students how to be attentive } \\
\text { to their listening. Deep listening reflected a high level of the "connected" dimension of } \\
\text { participatory literacies } \\
\text { Tinker with Tools: students were largely unfamiliar with the tools to create a podcast. Class time } \\
\text { must be dedicated to tinkering and teachers should draw on the distributed expertise in the } \\
\text { room. The format offers opportunity to develop collaborative, multimodal, and participatory } \\
\text { literacies over time. } \\
\text { Explore Platforms: teachers spent much time than anticipated exploring the different platforms fo } \\
\text { composing and publishing. Teachers need to examine the availability of features related to share- } \\
\text { ability, affordability, and accessibility as well as any school-based guidelines on privacy and } \\
\text { security. }\end{array}$ \\
\hline
\end{tabular}

The Canadian Journal of Action Research, Volume 22, Issue 1 (2021), 45-68 
For the 34 students who received the "Seeing is Believing" story versus the control group $(n=24)$ that received the informational text, the result was $90 \%$ more growth on a post-test than growth shown by the control group. For "Climate Change Game", there was $100 \%$ growth for students who received the story versus the control group. For the 31 students who received "No Paine, No Gain," the final result was 50\%.

The findings indicated that students who received all three stories resulted in greater comprehension and/or retention of information, compared to those in the control group. Despite an increased documented number of behavioral issues with students after lunch, students showed slightly higher comprehension and/or retention in post-lunch classes. Thus, there was a correlation between learning through stories and better overall performance; students receiving stories outperformed students not receiving stories, even if those stories did not individually show positive results over their informational text corollary.

\section{Project 3: Fostering Participatory Literacies in Language \& Literature with Student- authored Podcasts}

In today's digital landscape, teachers are expected to leverage digital media tools in their teaching. The purpose of this study was to examine how a podcasting unit in a $10^{\text {th }}$ grade Language \& Literature fostered digital literacies as an integral part of the curriculum. The central questions were:

(1) How does the podcasting unit support students in the process of making meaning, sharing ideas, and interpreting texts within and across multiple media platforms?

(2) In what ways does this project draw on and/or expand adolescents' participatory literacies?

(3) What new insights do we gain on the technical aspects of podcast production and pedagogical approaches? Recognizing the value of participatory literacies (Wohlwend, 2016) and connected learning (Ito, 2009), this study built on the belief that educators should integrate technology to foster the kind of digital literacies and draw on digital platforms to increase students' skills and foster interactive learning in the context of academic work.

This qualitative study focused on student-produced podcasts that were produced as part of the work in Charles's 10th grade Language \& Literature classroom. The learning unit was designed around social equity, wages, economic growth, and the American dream. The culminating project was a published podcast connected to the central themes of the unit. Drawing on students' audio-recorded podcasts, assessments of students' podcasts, and other artifacts, Charles and his faculty collaborator, Molly, found three themes.

Practice listening referred to the ways that the work required teaching the students how to be attentive to their listening. Charles and Molly found that deep listening reflected a high level of the "connected" dimension of participatory literacies. 
Tinker with Tools illuminated the need to dedicate class time to tinkering and to lean on the distributed expertise in the room. The format offers opportunity to develop collaborative, multimodal, and participatory literacies over time.

Explore Platforms surfaced how teachers spent more time than anticipated exploring the different platforms for composing and publishing. This study highlighted how teachers should examine the affordances of different sites in selecting a platform that matches the goals of the project. Charles and Molly also found that teacher educators must support aspiring English teachers in designing instructional activities related to digital media in the process of developing their literacies and young people's literacies.

These three projects all had a life cycle of their own. We came together after the projects were complete to collectively examine what this action research experience meant to us. Drawn from our in-person meeting notes and individual reflective memos, our team of three school-based practitioner researchers and two university-based researchers explored and co-constructed the meanings of our individual and collective experiences. Through thematic analysis, four themes emerged from the data: Infrastructure, We are All Partners in Education, Engaging Pathway for Experienced Teachers, and Challenges. In the next section, we share the four key themes.

\section{LESSONS LEARNED From ENGAGING IN THIS WORK}

Through our individual and collective reflections and analysis of the experiences of practitioners tied to three different action research projects, four ideas emerged as critical to the value of this kind of research, partnership, and professional development. The four findings surfaced from continued dialogue, writing, and exchange between and among the five co-authors. Our process was ongoing and recursive. Given that the five of us are located in different professional roles and professional contexts we engaged differently in various phases and components of both the action research program and the writing of our article, yet, we participated in this work together.

Taken together, the four themes offer insights into what made the collaborative action research opportunity appealing to CIHS practitioners and faculty and the potential benefits from participating in the voluntary program. The first theme, Infrastructure, highlights how the presence of a clear structure and sequence was appealing to experienced teachers. Second, We are All Partners in Education, emphasizes how the unique design, particularly the university-school partnership aspect of this program forged professional relationships that expanded the sense of connection/possible connection between high school educators and university educators. The next theme, Engaging Pathway for Experienced Teachers, speaks to how this action research program design of this action research program is wellsuited for enriching the professional dispositions, skills, and knowledge of seasoned practitioners. Finally, Challenges, captures some of the big-picture obstacles and difficult questions that surfaced in this work, including our own challenges in preparing this article. 


\section{Infrastructure}

At several points throughout our collaborative inquiry into this action research program, the three co-authors who are full-time teachers shared examples of their decision to participate as well as the nature of their experience that highlighted the importance of the infrastructure of the Cleveland State University (CSU) Action Research Program. Based on ideas that were shared in both dialogue and writing, it was clear that all three practitioner researchers appreciated and leveraged the existing structure, sequence, and process developed and laid out by the university-based program. Since participation was voluntary, we wanted to gain a better understanding of why practitioners made time for this project. Although practitioner participants expressed a range and variation of reasons, most reasons were connected to the value of joining a program with a clear process and yearlong map.

In response to being asked why they, the three practitioners, joined the program, they shared several ideas about the program framework timeline and the end-of-project showcase. For Charles, John, and Sarah, three experienced teachers, the action research was appealing because there was an established plan and structure for partnership in place. The program provided the foundation and some consistency for their pursuit. Yet, the structure did not strictly prescribe the content of the projects or the focus of research questions. Given that the structure came with the benefit of existing partners and some funding sources, it took out some of the outreach and relationship building that would be typically required when initiating a research project. As described earlier in the context, the program would manage the pairing process (Phase 1) between the practitioners and the university faculty. This step brought some efficiency to the process, especially for practitioners, as it eliminated the beginning stage of forging a personal connection with a university faculty member. This step allowed them to transition into the research process quickly.

Furthermore, participation in the project works to foster and/or deepen the relationships between high school educators and university educators. Although there are many schooluniversity partnerships around the country, it is not always clear how to build connections or how a high school faculty might start a project with a university faculty member. Similarly, many university faculty want to be connected to PK-12 practitioners in schools, yet it is unclear how they could be involved with or enter into work in schools. This program built a bridge and the facilitation of school-university pairings expedited a path for school-university relationships and collaboration. As a reflective practitioner, Sarah already examined her teaching regularly, yet, as highlighted in the comment below, the program provided a platform for her to crystalize and pursue her ideas further as a result of being paired with a thought partner. Sarah wrote:

I like to take walks or go for a run after school just to think about how things went well or poorly, what I could do better in the future, etc. But that's pretty much where it stops. And, so, being asked to formalize and legitimize those thoughts and reflections was helpful. 
The role and significance of the program's infrastructure were evident in John's project. For John, the concrete invitation, clear timeline, distinct program phases, and existing partnership pairing structure emerged as a kind of tipping point for his long-held professional inquiry and professional interest. John shared: "It has offered me the motivation and structure to prepare materials for my students that I have desired to create for a long time." For John, the project did not introduce something completely new, but it created the space for him to return to a question and an interest that he first developed when he was a graduate student several years prior. The action research program surfaced as the moment to finally return to his question and launch the project. John wrote: "By writing these stories, I have gotten back into the habit of writing fictional stories; this has helped my growth as a professional and also improved my understanding of the crux of my research." Collectively, we found this was important because the infrastructure prompted progress. The project offered motivation to return to early professional interests, but in the context of John's current classroom. His commitment helped him return to his story writing in the service of innovative curriculum development. Although John had thought about this for years, the project gave him additional motivation to initiate the project. This finding seemed particularly important because John, Charles, and Sarah, three experienced and motivated practitioners, had a large number of ideas and questions to consider, but the structure added the motivation, accountability, and some clear way forward with one of the ideas.

\section{We are All Partners in Education}

This finding refers to how this project fostered and facilitated partnership. Partnership manifested itself in several ways and on different levels. Although it is not surprising that partnership surfaced as a key component of this work, some of the nuances of what this partnership looked like and why the partnerships mattered for practicing teachers are less familiar. Three different levels of partnership emerged within this theme: Critical Friend, Institutional Level Partnership, and the Professional Field at Large.

\section{Critical Friend}

This process created the opportunity for practitioners and university faculty to develop critical friends for their professional work and research interests. The design of the program allowed for ongoing dialogue and interactions. For example, interactions provided practitioners a chance to discuss their own practices which helped crystallize some questions that they thought about all the time but did not necessarily stop to investigate in a systematic way. Interactions provided faculty a chance to consider the complexities of classroom implementation and ways to be responsive to everyday challenges. Sarah appreciated the opportunity to explore existing ideas, practices, and questions in depth with a thought partner. Interested in examining a question deeply related to her practice, but outside her academic content area, she was able to explore the inquiry with Molly, who also thought about education and school culture. Sarah shared, "I had access to great minds at a university that made it much more valuable and encouraging ... My conversations with you [Molly] are always so encouraging and insightful and I appreciate the academic aspect brought to the conversation." 
Charles indicated that he appreciated the sustained support and insights from faculty around the review of the relevant literature and existing research. Further, Charles noted, "If you get a good partner from CSU, it can be really inspiring. Always wanted to try something? This gives you the opportunity." Charles, a teacher with 27 years of experience, has regularly inquired into his practice and is committed to trying new things in his classroom. This partnership supported his professional curiosity with Molly as a thought partner.

We also learned that working with partners from diverse backgrounds enriched the action research process, with a different lens on the content with possible different skill sets and strengths. John shared how different partners factored into the evolution of his project. John wrote:

When I first undertook this project, I was working as a MUST [graduate] student with both my mentor teacher and also CSU faculty. I was able to receive guidance from these mentors, and also the support that this unique thing that I was trying to do was worth the time and effort.

In addition to university faculty as critical friends (Nelson, 2008), John also mentioned that his high school students took on a role as critical friends. He indicated: "The students have given me useful feedback, since they are action researchers themselves and understand explicitly the connection between research and improving knowledge of themselves and their own learning."

On top of the intellectual exchange, critical friends could serve as inspirational partners, cheerleading their co-researcher throughout the research process. Sarah mentioned: "I think I needed the encouragement of someone else." Charles noted the opportunity to secure resources to support his work because of the relationship and interaction. For example, Charles's project was awarded a small grant that provided funds to support the presentation of this work at a national conference. It was clear that developing critical friends among PPK-12 practitioners in schools and university practitioners underscored the importance of this action research partnership within the school-university pair.

\section{Institutional Level Partnership}

At the institutional level, specifically between the high school and the university, we found that this work benefited the development of a sense of shared responsibility for educating young people. There is often a disconnect between high school and college teachers in the sense of thinking about the academic abilities and skills that young people have when they begin their college careers. We find this disconnect problematic and troubling in terms of creating a sense of unity and collaboration between PPK-12 and university educators. Oftentimes, there is a perception that high school graduates do not come to college as "prepared" as necessary for college-level work. This perception puts the onus of responsibility on the high school teachers, positioning them as not doing their work at a satisfactory level. This positionality can create tension between high schools and universities as opposed to seeing themselves as part of the same educational system and 
path. Charles shared that the deliberate pairing of practitioners with university faculty fostered "mutual respect" between PPK-12 and university educators. This partnership did not elide all of those challenges and at times perpetuated it, yet we did find that it created room to see one another as partners in PK-16 education.

This example highlighted the ways collaborative action research could be seen as a strength-based approach for school-university partnerships. As implied in Charles's comments, there can be a tendency to blame the educators that came before you when students do not have the skills or capabilities you expected. This collaborative design, however, forged interactions between high school and university educators that created a way for both groups to see the connections between their work.

By spending time with her school partners, Molly was able to see and examine some of the pressing questions and challenges in Charles's and Sarah's classrooms. On the other hand, school-based educators gained new insight into university faculty's work. Ultimately, both parties were able to understand and appreciate one another's work in a new, more personalized way. The actual experience of working together to examine and address challenges with a goal of improving our instructional practices deepened our capacity for seeing one another as partners in a PK-16 continuum. We found this to be an example of how this kind of collaboration challenges the construction of a division between "theory" and "practice" or the one-directional notion of "theory into practice" and instead supports the idea of a "theory of practice." This intellectual merger across two institutions moved our school-university partnership to a new level.

\section{Professional Field at Large}

This work positioned all of us, school and university educators alike, as knowledgeable and valuable partners in the field of education. For example, we proposed and presented our work together at professional conferences. Charles and Molly have presented different outgrowths of their partnerships at several conferences. As a team, the five of us copresented our work at the regional chapter conference of the American Educational Research Association (AERA). At that session, several audience members were interested in John's storytelling project in the Biology classroom work and he provided openly accessible QR codes for his stories and storytelling approaches. Some participants stayed after the presentation to inquire further about his work and showed enthusiasm to learn more about his future implementations.

Sarah and Molly presented findings from Sarah's study on the attributes and experiences of students who are in an inaugural class of a new school. Grace and her partner co-presented their work on studying the experiences of refugee students in an afterschool program. Finally, Charles and Molly co-presented on their podcasting project at another national convention, where they were invited to write a chapter about their work. This chapter is now published and available to professionals interested in podcasting in the classroom (Buckley-Marudas \& Ellenbogen, 2019). This finding highlighted that the work was immediately relevant to the field and that practitioners' novel, real-time research made 
valuable contributions to the field in education.

\section{Engaging Pathway for Experienced Teachers}

We found that this CAR process surfaced as an engaging and meaningful way for experienced teachers to improve and enrich their practice. John, Charles, and Sarah, the three practitioner co-authors, are well-documented as successful and effective educators. Yet, all of them saw themselves as life-long learners who were committed to ongoing improvement in their practice. Many of the district-sponsored PD opportunities, understandably, tend to focus on supporting and developing practitioners in their early years of teaching and are, therefore, not a great fit for experienced educators' professional pathways. It is also common for many of the most successful and motivated veterans to be encouraged to pursue administrator roles as a natural next step to expand their leadership potential.

Many teachers, however, want to find ways to lead from the classroom, focusing on improving their own classroom practices and finding ways to deepen their work and impact in the school and field as a teacher leaders. The CAR seemed to be a compelling pathway for experienced practitioners for their professional pursuit. The pathway opened new pathways, for all of us, for writing about and our work in different professional outlets.

\section{Teacher-Driven PD}

This CAR program was designed to let the content of any inquiry be teacher-driven. Although there was a built-in structure and the program delineated a timeline with distinct phases of the research process and matched practitioners with a university faculty member with a certain area of expertise, the practitioner researcher was positioned as the project driver and organizer. As a result, the teachers had autonomy over the research design and learning process. For John, this meant choosing to revive a research question that he developed as a graduate student several years ago. Sarah emphasized her action research experiences meeting her professional inquiry and growth needs. She wrote:

This was a much more engaging PD experience because I was able to research and study what I wanted to, what was interesting to me, and what I thought would be valuable. (It sounds so self-centered!) But, truly, it was empowering in that way. It also felt valuable, when so often required and non self-directed PD doesn't. I think opening up this opportunity has also let my imagination run free for what I will do in the future.

Sarah's reflections revealed action research as an individualized PD that was personally meaningful and encouraged further inquiry. Across the comments shared by Sarah, John, and Charles, it was clear that driving their PD around an inquiry question of their own was an engaging and stimulating professional opportunity. Charles shared that researching and writing with a university partner became a way to support his continual professional learning. John highlighted his action research experience on its individualized nature and flexibility. He also noted that the process was active. For example, the program supported 
him in the actual development of curriculum materials that could be implemented in his classroom.

John described the program as "sustained" and "focused". At the same time, John had the autonomy to carve his own path. Elaborating on the characteristics of the program that appealed to him, he explained: "It was energizing - to try something new, to have 'permission' to struggle, the students saw themselves as part of the research." This referred to the fact that the students understood that John was inquiring into this project and wanted to learn from his work. The program was structured so participants would focus on one project and a specific line of inquiry. John noted that he felt supported and encouraged to use this space to try a new practice. As co-author Grace noticed in her reflection of John's engagement with the partnership, the meetings with the paired faculty were not the top priority. Instead of meeting with a paired faculty member, John developed his project independently at the research level and collaboratively at the programmatic level in terms of leveraging the program infrastructure, milestones, presentation, and scholarship.

Sarah indicated the benefit of having the freedom and flexibility to figure out what she really wanted to study. Although she first drafted some preliminary questions related to teaching in her content area of Spanish, and was first paired with a faculty member wellversed in Spanish language teaching, Sarah was, at the moment, deeply curious about a question related to school culture. This program, given its broad emphasis on supporting practitioners' burning questions and interests, offered Sarah the flexibility to change course and study a question about the school environment. Sarah was then paired with Molly, who has a background in educational policy, organization, and leadership. The new pairing encouraged Sarah to investigate an area that she would not have explored and that addressed her inner professional curiosity. The program's encouragement for practitioners to follow their interests and questions validated their questions as important and relevant.

For experienced teachers, especially for those who excel in their own teaching practices, engaging PD opportunities are often more difficult to find and arrange. This program's intentional design as a practitioner-driven PD model supported individual growth in a collaborative setting. As practitioners choose topics and inquiries that they are passionate about, their PD work becomes meaningful, as indicated by these teachers. This program offered flexibility and honors teachers' individual inquiry.

\section{A Professionalism Builder}

The action research process was a professionalism builder in various capacities including professional knowledge, scholarship skills, disposition, and motivation. John underscored the ongoing development of scholarship skills. He indicated the development of his scientific research skills and scholarship skills, including his public speaking skills. This process helped him focus on research validity, including data size and control groups, thus offering additional supporting evidence of this research skill building. In addition to providing the platform for the action research process, the program encouraged school practitioner-university faculty co-scholarly experience, an uncharted territory for many practitioners. Sarah shared "it put me in touch with a whole research community that I, 
honestly, didn't even know existed."

As to the professional dispositions building, John shared that his involvement cultivated his collaborative skills and risk-taking character. Charles indicated that his participation strengthened his confidence in his work and offered him opportunities to disseminate his work at professional research conferences. Sarah highlighted the validation of the value of her practice. She wrote:

It was incredibly valuable to me to be asked to do this. I don't always have a lot of confidence that what I am thinking or reflecting on or learning in the classroom would naturally be valuable or interesting to someone else. It's not a lack of selfesteem - more just that I don't always feel particularly innovative.

Practitioners also developed their professional knowledge. John described that the program created opportunities for him to disseminate the new knowledge he generated and the chance to receive constructive feedback. He envisioned the expansion of his new knowledge to the larger community. He elaborated on his instinct to focus on research expansion to other schools. Charles shared that this collaborative experience supported him to try new practices and consider alternative pedagogical approaches with his Language \& Literature teaching. He valued the experience of having a thought partner to support and expand his work and to disseminate the work within the larger professional community.

\section{Challenges}

The final lesson that emerged in our analysis of participants' action research experiences was best characterized as Challenges, including the role of Time and Credit for engaging in this program, and a tension surfaced that we came to refer to as Missed Opportunities.

\section{Time \& Credit}

Although we found several benefits to practitioners' involvement in this action research program, there were challenges. Committing to this program required time. The program was introduced as an opportunity to look closely at one's practice. CAR program participants were encouraged to examine what was already taking place in their practices rather than starting something entirely new. Yet, project development and program participation required additional work. Even if teachers were collecting data as part of their teaching, additional time was needed for the data analysis, PD sessions, and presentation of findings on the part of the practitioners and university faculty. Charles mentioned time constraints as one of the primary challenges of his participation. With the school principal's support, there were instances when existing professional learning time was dedicated to the action research program, but most of the work took place at other times. All practitioners suggested that the action research program be integrated further into the existing PD infrastructure in order to account for some of the work time. It was also recommended that the work be counted as Continued Education Units and, as of this writing, this option was in place. 
Missed opportunities surfaced in and through the process of our work as a team of coauthors, especially during the process of writing this manuscript. There is no question that our different positions and positionalities surfaced as we worked on making sense of this experience and as we started to write. During a video-based meeting about one of the drafts, Charles called attention to the tone and perspective of the draft. In the margins of an early draft, Charles wrote:

It seems to me that there is a tone problem here - that the words partnership, etc. keep coming up, yet the emphasis is on what the help of the professors allowed the teachers to do. If nothing was gained by one side of the equation, then I think it can hardly be called a partnership. There are things to be gained [by both sides].

Charles's comment proved to be an immensely helpful moment for our team and one that has implications for further examination of the value of the collaborative aspect of this work. It also raised attention to some of our habitual ways of working. As Charles highlighted, and John and Sarah agreed, the draft's central focus on what the three practitioners gained conveyed a unidirectional relationship between faculty and practitioners, with the direction, unintentionally, moving from faculty to practitioners. The two faculty, Molly and Grace, had recognized the focus on practitioners' experiences, yet the intent behind their focus on practitioners' experiences and what practitioners' gained was not to position this project as something "given" to practitioners by the university, but rather to highlight the potential professional learning and value of the work for experienced teachers. The hope was that this would make a case to schools district leaders and/or school administrators to support and integrate this kind of work as part of a school culture. By not including views from both sides of the research teams, however, it elided the collaborative aspect of the work, and unintentionally reified what Molly and Grace see as a problematic construction of the school-university relationship. This moment prompted additional reflections on the nature and value of this experience and how we positioned ourselves as co-authors.

Part of this oversight unfolded in light of the different roles we took during the inquiry and, specifically, the writing process. Although all of the early meetings took place in person, as a whole team, at the high school, much of the writing unfolded individually. We all contributed different pieces to the writing, yet we agreed as a team that Grace and Molly would take the lead on the final drafting stages of the manuscript. Given our different workloads and the time associated and allocated for different elements of our daily work requirements, Grace and Molly dedicated time moving the outlines and early skeleton drafts into a more polished draft with the understanding and agreement that we would read and come together to collectively discuss and revise the drafts in progress.

\section{Missed Opportunities}

We recognized the missed opportunities as a challenge, yet it has enriched the work and generated new questions. As faculty partners, Molly and Grace both reflected on this critical moment. Grace reflected: "As I conducted the literature review, I had gained insights into the benefits of university faculty as critical friends to the practitioners in the 
CAR process. My [practitioner] colleagues indicated that the literature conveyed a hidden message to them." This moment illuminated important questions about who the beneficiaries were during the process. For example, are teacher practitioners perceived or positioned as the sole beneficiary in the process? Furthermore, this shed a spotlight on who played the critical friend role.

Grace shared: “It didn't occur to me while writing until my partners' inputs. As I reflected, I learned that much of my focus was on how the research process supported the practitioners rather than their contribution in this process." The mutual benefits to both parties were critical during the collaborative process and the program was built on the belief that parties in both institutional contexts brought strengths to the table. Yet, it became clear that this was not reflected in the original framing of the writing. This level of collaboration needs to be acknowledged or it overlooks a tenet at the core of the program. Although the aim of this article was to examine current practitioner researchers' experiences, the learning and development that occurred on both ends in this partnership cannot be overlooked. It is important to be intentional in valuing and acknowledging this professional dynamic and growth. Thus, further examination of university faculty's experiences and the benefits gained is needed.

As the piece developed, Molly had focused largely on practitioners' experiences, almost leaving herself out of the reflections on the development and progression of the teacherdriven projects. In a subsequent reflection, Molly wrote:

I was eager to hear what current full-time practitioners found to be useful and valuable in their participation in the program. As a result, the lens was directed almost exclusively to the reflections and insights from John, Charles, and Sarah.

The intent was to foreground and center the school-based practitioners' experiences and honor what they saw, felt, and learned. Molly and Grace hoped that by zooming in on what veteran teachers, in their own words, believed that they gained from the experience, that school and university-based researchers, as well as district leaders, could better understand how action research might be a worthwhile approach to professional development and learning, especially for veteran teachers. Yet, as Molly and Grace reflected on this framing, it became evident that the perspective reflected a bigger question about the collaborative processes of the program and a missed opportunity to engage in the same reflection and analysis of what other participating university faculty-were learning and gaining from the experience.

In addition to tending to overlook much of the faculty experience in the partnership, Molly also reflected on what she gained as a faculty participant in this program. In her collaboration with Charles on the podcasting project, Molly spoke about the insights she gained on the nuanced processes of rolling out and refining a unit plan, especially around the technical support that was needed along the way. Although Molly had supported several podcasting projects in the past and had thought a great deal about podcasting, she had not seen or led a podcasting unit from start to finish in a high school classroom. For 
example, during the review phase, there were several student files that would not play. Furthermore, students would need additional guidance and teaching on how to attend to small details around sound quality with audio interviews so that the recordings would be audible in the final podcast.

Molly's participation confirmed the idea that teachers can still be learning some of the technologies when the project starts, but they do need to take extra time in the classroom to tinker and troubleshoot. Molly gained several new ideas on how to revise her digital storytelling project in a teacher education course she teaches at the university, as well as several new resources and ideas for unit planning that she would share with pre-service teachers who often share that they want to design inquiry-based and innovative units, but feel restricted by state standards.

In collaboration with Sarah, Molly expanded her knowledge on new school culture. She had some experience with school design efforts, yet, as Sarah learned in a review of the literature, the work rarely focused on the experiences of the inaugural class. There is little question that the first few years are critical to the ongoing development of the school and set the tone for school culture, but little attention has been paid to what the students or teachers feel about paving that pathway. All of the students as well as administrators, teachers, and families wanted the inaugural class to have positive experiences, but it was often overlooked by the long-term goals. Molly gained a rich example of the nuances of school culture that informed the school context and found it very helpful to think with Sarah about the unique characteristics of students who are always in the 'lead' as well as the disconnect between different stakeholders' opinions of the identified characteristics. This insight has been very helpful in Molly's conversations with pre-service teachers about the salience of school culture.

\section{Closing ThOUghts AND QUESTIONS FOR FURTHER INQUIRY}

This work has implications for PPK-12 school and university communities in the areas of PD and partnership. The experiences put forth illustrate the potential power of inviting all teachers, but especially experienced teachers, to engage in action research projects as professional development and learning. The practitioner-driven nature of the work offers a promising alternative to many of the existing PD opportunities that may feel less relevant or less connected to a practitioner's interests and needs. The practitioner-university faculty collaborative efforts strengthen the PD by bringing a different lens, insights, and momentum. The work also has the potential for practitioners to share their findings and their knowledge with the field in the larger professional community. Given the role of infrastructure and resources support, and a programmatic sequence, we hope that this project offers new ideas for ways to further develop or extend existing school-university partnerships.

Recognizing that inquiry both stems from and generates questions, this work has raised new questions and areas for further inquiry. Here we highlight specific areas of research that could add to the existing body of knowledge. Regarding Partnership, the ongoing study 
of the impact of PK-12 school-university partnerships is critical to address questions such as:

- What does the partnership mean through the lens of the practitioners or university faculty?

- How are the collaborative experiences similar and different for practitioner and university faculty?

- In what ways are the partnerships bi-directional or reciprocal?

This work also raises questions about the construction and conceptualization of Critical Friends:

- Who plays the role of critical friends in the collaborative action research process? (Most studies focus on university faculty as critical friends, but we recommend further inquiry on the practitioners' roles as critical friends.)

- Although it is significant to complete the collaborative action research project and share work with the professional community, what comes next?

- How could we maximize the partnership and role of critical friends to support the continual growth?

- How does the work or the learning take on life after the dissemination?

Further explorations in these areas will enhance our understanding and yield new insights into collaborative action research processes, particularly within a school-university partnership.

\section{REFERENCES}

Ado, K. (2013). Action research: Professional development to help support and retain early career teachers. Educational Action Research, 21(2), 131-146. https://doi.org/10.1080/09650792.2013.789701

Ball, D. L., \& Cohen, D. K. (1999). Developing practice, developing practitioners: Toward a practice-based theory of professional education. In L. Darling-Hammond, \& G. Skyes (Eds.), Teaching as a learning profession: Handbook of policy and practice (pp. 3-32). San Francisco, CA: Jossey-Bass.

Bransford, J. D., Brown, A. L., \& Cocking, R. R. (2000). How people learn: Brain, mind, experience, and school. Expanded edition. Washington, D.C.: National Academies Press.

Bruce, C. D., Flynn, T., \& Stagg-Peterson, S. (2011). Examining what we mean by collaboration in collaborative action research: A cross-case analysis, Educational Action Research, 19(4), 433-452. 
Buckley-Marudas, M. F. \& Ellenbogen, C. (2019). Fostering participatory literacies in English language arts instruction using student-authored podcasts. In J. Mitchell \& E. Vaughn (Eds.), Participatory literacy practices for P-12 classrooms in the digital age (pp. 20-39). IGI Global.

Calhoun, E. F. (2002). Action research for school improvement, Educational Leadership, 59(6), 18-24.

Carrington, S., \& Robinson, R. (2004). A case study of inclusive school development: A journey of learning. Inclusive Education, 8(2), 141-153.

Cochran-Smith, M., \& Lytle, S. L. (2009). Inquiry as stance: Practitioner research for the next generation. New York: Teachers College Press.

Cooper, C. W., \& Gause, C. P. (2007). "Who's afraid of the big bad wolf?" Facing identity politics and resistance when teaching for social justice. Counterpoints, 305, 197-216.

Deuchar, R. (2008). Facilitator, director or critical friend? Contradiction and congruence in doctoral supervision styles. Teaching in Higher Education, 13(4), 489-500.

Foulger, T. S. (2010). External conversations: An unexpected discovery about the critical friend in action research inquiries. Action Research, 8(2), 135-152.

Gordon, S. P. (Ed.) (2008). Collaborative action research: Developing professional learning communities. New York: Teachers College Press.

Herrera, L. J. P. (2018). Action research as a tool for professional development in the PK-12 ELT classroom. TESL Canada Journal, 35(2), 128-139.

Ito, M. (2009). Participatory learning in a networked society: Lessons from the Digital Youth Project. Presentation for the 2008 Annual Meeting of the American Educational Research Association Presidential Session. Retrieved from http://www.itofisher.com/mito/publications/participatory_l.html

Kayaoglu, M. N. (2015). Teacher researchers in action research in a heavily centralized education system. Educational Action Research, 23(2), 140-161.

Kember, D. (2000). Action learning and action research: Improving the quality of teaching and learning. London: Routledge.

Kemmis, S., \& McTaggart, R. (2005). Participatory action research: Communicative action and the public sphere. In N. K. Denzin \& Y. S. Lincoln (Eds.), The Sage handbook of qualitative research (pp. 559-603). Sage Publications Ltd. 
McLaughlin, C., \& Black-Hawkins, K. (2004). A schools-university research partnership: Understandings, models and complexities. Journal of In-Service Education, 30(2), 265-283.

Mitchell, J. (1984) Typicality and the case study. In R. F. Ellen (Ed.), Ethnographic research: A guide to conduct (pp. 238-241). New York: Academic.

Nagda, B., Ratnesh A., Gurin, P., \& Lopez, G. E. (2003). Transformative pedagogy for democracy and social justice. Race Ethnicity and Education, 6(2), 165-191. https://doi.org/10.1080/13613320308199

Nelson, E. (2015). Opening up to student voice: Supporting teacher learning through collaborative action research. LEARNing Landscapes, 8(2), p.85-299.

Noffke, S. E. (1997). Professional, personal, and political dimensions of action research, Review of Research in Education, 22, 305-343.

Oja, S. N., \& Smulyan, L. (1989). Collaborative action research: A developmental approach. New York: Falmer Press.

Razfar, A. (2011). Action research in urban schools: Empowerment, transformation, and challenges. Teacher Education Quarterly, 38(4), 25-44.

Reischl, C. H., Khasnabis, D., \& Karr, K. (2017). Cultivating a school-university partnership for teacher learning. Phi Delta Kappan, 98(8), 48.

Swaffield, S. (2007). Light touch critical friendship. Improving Schools, 10(3), 205- 219.

Van Driel, J. H., Beijaard, D., \& Verloop, N. (2001). Professional development and reform in science education: The role of teachers' practical knowledge. Journal of Research in Science Teaching, 38(2), 137-158.

Vanderhye, R. (2015). 3 essentials to motivate and retain veteran teachers. Principal, 94(4), $40-41$.

Wennergen, A., \& Ronnerman, K. (2006). The relation between tools used in action research and the zone of proximal development. Educational Action Research, 14(4), 547-568.

Wohlwend, K. E. (2016). Who gets to play? Access, popular media and participatory literacies. Early Years: Journal of International Research \& Development, 37(1), 6276.

Yin, R. K. (2003). Case study research: Design and methods (3rd ed.). Thousand Oaks, CA. 
BIOGRAPHICAL NOTE:

Mary Frances (Molly) Buckley-Marudas, Ph.D., is an associate professor in the Department of Teacher Education at Cleveland State University. Her research interests include youth-led research, adolescent literacies, digital literacy, and English education.

John Dutton currently teaches science and computer science at the Campus International High School in Cleveland, Ohio. His research interests include storytelling in science, computer science instruction, and science instruction.

Charles Ellenbogen is a Language and Literacy teacher at Campus International High School in Cleveland, Ohio. His research interests include equity and justice in the classroom, English language arts instruction, digital literacies, and youth participatory action research.

Grace Hui-Chen Huang, Ph.D., is an associate professor in the Department of Teacher Education at Cleveland State University. Her research interests include collaborative action research (CAR) and professional development for PK-12 school practitioners; Parenting practices and parental learning involvement of urban families, Asian families, and refugee families; and family-school relations.

Sarah Schwab teaches World Languages (Spanish) at the Campus International High School in Cleveland, Ohio. Her research interests include school culture, and world language instruction. 